\title{
DOS CABILDOS DE ALTA REPRESENTACIÓN: SEVILLA Y SANTIAGO DE LOS CABALLEROS
}

\author{
por Adelaida González Vargas
}

\begin{abstract}
Consiste la presente exposición en una muestra de Ceremonial Comparado relacionando el Cabildo Secular de Sevilla con el de una ciudad hispanoamericana. Se da cuenta de algunas influencias del Ayuntamiento Hispalense sobre el de Santiago de Guatemala, añadiéndose ciertas coincidencias en el trato de la función de la ceremonia dentro de la antigua etiqueta de ambas instituciones. Abarca la síntesis la época más representativa de los viejos ceremoniales, desde mediados del siglo XVII hasta fines de la centuria del setecientos.
\end{abstract}

The present paper is concerned with Comparative Ceremonial, examining the Secular Council (Cabildo) of Seville in relation to that of a city in Hispano-America. Some of the influences of the Corporation of Seville on that of Santiago, Guatemala, are described, together with some coincidences in the treatment of the ceremonial function within the ancient conventions of both institutions. This review covers the most representative period as regards ancient ceremonial, from the mid 17 th century to the end of the $1700 \mathrm{~s}$.

Al considerar las características que en materia de ceremonial tuvieron los cabildos seculares de Sevilla y Santiago de los Caballeros de Guatemala, durante buena parte de la Edad Moderna, hemos encontrado curiosas similitudes.

Debemos advertir que cuando hablemos de relaciones entre estos dos organismos, no excederán de una aproximación y aún debemos admitir que en otras ciudades hispanoamericanas hayan podido ser de un mayor interés tanto los paralelismos como las influencias. Ocurre, sin embargo, que desde un punto de vista etnográfico tal y como queremos dar el justo enfoque a la exposición, se cuenta con estudios publicados en el campo que nos ocupa, sobre temas análogos o parecidos. Ellos nos han servido de una primera base para el complemento de la investigación documental.

Nos vamos a ceñir brevemente al período histórico durante el que, tanto en la Península como en las Indias Españolas, se tomó verdadera conciencia del problema de las etiquetas. Es decir, desde mediados del siglo XVII hasta fines del XVIII, dado que ya a estas alturas se había consolidado y era patente el gran peso de la tradición y de las ocurrencias de actos oficiales llegándose incluso a imprimir libros, crónicas y reglamentos de ceremoniales, costumbre 
esta que fue perdiéndose poco a poco a medida que se debilitaba el uso de la antigua ceremonia. Como soporte fundamental de estos hechos queremos destacar tres notas que dan el propio marco y juego a la función de la cortesía, tan íntimamente ligada a la vida municipal y tan apreciada, digamos que exageradamente, por los Cabildos y Regimientos.

Nos referimos, en primer lugar, al hecho de OSTENTAR LA REPRESENTACIÓN DEL PUEBLO, la que precisamente les va a proporcionar su mayor rango y prestigio hasta el punto de identificarse con él y llegar a autotitularse "La Ciudad", fundirse y hasta confundirse con ella en la imagen de sus salidas públicas. $Y$ es que, tanto el aplauso como el rendido acatamiento de los vecinos les importaban a estos antiguos ayuntamientos sobre todas las cosas, y así, por ser de hecho su propio símbolo, se convertía sin género de duda, en la primera fuerza viva del ámbito ciudadano, especialmente en el aspecto que vamos a considerar.

Pesaba mucho en los regidores, aunque en un segundo término de importancia, la grave responsabilidad de ser los ADMINISTRADORES más directos del vecindario, tanto de los bienes de propios, como, en un primer momento, de la justicia, en el verdadero sentido definitorio de estar al servicio de la comunidad, dejando a un lado los aspectos que hoy día confundimos muy frecuentemente con "lo burocrático" cuando hablamos de la Administración en general.

Finalmente, es muy de señalar que ambas ciudades, al fundarse, contaban con un reducido núcleo de nobilísima gente, escasa población y, formando parte de ella, un colectivo que podemos llamar de vencidos o conquistados, aunque en las Indias formasen los primeros un conjunto de distintos matices sociales por su alejamiento del Viejo Mundo ${ }^{1}$.

De este grupo de nobles, de reciente hechura, surgieron los componentes de la institución municipal, porque pudieron acaparar los oficios concejiles con suma facilidad y sin competencias, sobre todo, como decimos, en la primera hora de las fundaciones de núcleos urbanos de origen castellano común. Estos individuos de la nobleza que saltaron los primeros a formar parte de los cabildos, por su cualidad de conquistadores o reconquistadores en uno u otro caso, se convirtieron en los legítimos receptores de los más altos privilegios reales, por todo lo cual y en función de ellos, se extremaba la categoría del Cabildo Secular, cuya estampa, ya veremos, quedó ennoblecida, por obra y gracia del ceremonial, en la mente de todos.

Una vez sentados estos principios, nos proponemos a continuación destacar sobre todo los privilegios municipales y la indómita postura que los ayuntamientos se vieron obligados a adoptar, haciendo gala de su intransigencia para no ver postergada su clase y alta condición, aun sin estar amparados en múltiples ocasiones ni por la razón ni por la ley.

1. V. Sanchíz Ochoa, Pilar: Los Hidalgos de Guatemala. Sevilla, 1976. Cap. IV. 
Dicha tensión fue una constante en los Cabildos Seculares de Sevilla y Santiago de los Caballeros, cuyo malestar, digámoslo de paso, no disminuyó nunca la alegría de las celebraciones festivas que se organizaban por ellos mismos. De los guatemaltecos dice el P. Bayle que eran gente alegre y que se perecían por las fiestas ${ }^{2}$, y en cuanto a Sevilla, es notorio que adquirió, desde fechas muy tempranas, la universalidad y la fama en este punto. Fiestas todas ellas inventadas por los propios miembros del Ayuntamiento, sostenidas de sus escasos bienes y, según los cronistas, con increíbles resultados de pompa y magnificencia.

De la ceremonia dice el Diccionario de la Real Academia de la Lengua que es "acción o acto exterior arreglado por ley, estatuto o costumbre para dar culto a las cosas divinas y honor a las profanas". El acto cortés o ceremonioso, decimos nosotros, se convierte en una verdadera función cuando se practica por la entidad pública.

Estamos considerando dos ciudades tituladas ambas en principio "Muy Nobles y Muy Leales", empeñadas en practicar una etiqueta y protocolo de ostentación.

Sevilla, que se regía por el fuero toledano, ya lucía en su escudo de armas estos dos preciados títulos antes de mediar el siglo $\mathrm{XV}^{3}$. Santiago de Guatemala era también "Muy Noble y Muy Leal" por concesión de Felipe II en $1566^{4}$.

El Ayuntamiento Hispalense tenía adquirido, con fuerte consolidación y orgullo, el privilegio real de usar mazas desde $1438^{5}$. Saberse poseedora de tan alto rango da a la entidad titular un status de los más cotizados aún hoy día por las primeras instituciones oficiales de cualquier ciudad que se precie de importante. Se explica, porque las mazas constituyen nada menos que el símbolo de la dignidad. Se las dio a nuestra ciudad "para siempre jamás" -así lo estampa el documento- el Rey Don Juan II en carta al Concejo Hispalense de cinco de diciembre de dicho año, y las encargó el Cabildo, según consta en los anales, de plata y cinceladas, al orfebre Juan de Córdoba. De plata, asimismo, fueron las de Santiago de los Caballeros, pues dice la glosa que "Su Magestad le hace la merced de que pueda el Cabildo hacerse acompañar perpetuamente de maceros, con mazas de plata, en toda asistencia, paseo o festividad". La concesión data del doce de septiembre de $1600^{6}$.

Curiosamente Santiago había utilizado mazas, de un modo provisional, con simple licencia del Presidente de la Audiencia, antes de la concesión referida. Ello ocurrió en la asistencia pública del Cabildo a las honras fúnebres de Felipe II. Y bien se entiende la impaciencia, pues la ciudad venía de largo

2. Bayle, Constantino: Los Cabildos Seculares de la América Española. Madrid, 1952. págs. 685 y 688.

3. González Vargas, Adelaida: El Ceremonial del Cabildo Municipal Sevillano. Sevilla, 1967. pág. 30.

4. Pardo, J. Joaquín: Efemérides de la Antigua Guatemala. Guatemala, 1944. Año 1566, 21 diciembre.

5. Guichot y Parody, Joaquín: Historia del Ayuntamiento de Sevilla. Sevilla, 1896. Tomo I, pág. 153.

6. Pardo, op. cit. 
tiempo empeñada en conseguir esta merced por ser inmediata en categoría y condición a la de México, por la Real Audiencia que en ella residía, lo populoso de su ámbito urbano, el ser cabeza de seis provincias y el tener cuatro obispados? . Es verdad que estando formada por gente de tanta nobleza no podía quedar disminuida la representación sin ir "bajo mazas" en tan solemnísimo acto que fue sumamente famoso, tanto en España como en las grandes ciudades indianas. Recordemos aquí el estrepitoso escándalo que ocurrió en la Catedral de Sevilla en tales exequias (1598) por choques del Cabildo Secular con otros estamentos, cuyo origen fue precisamente una cuestión de etiqueta ${ }^{8}$.

Hemos comprobado que nunca más se va a poner en duda que ambas ciudades, cuyo comentario nos ocupa, entraban y salían bajo mazas de sus Casas Capitulares para asistir a los actos públicos, y que "las levantaban" en señal de acatamiento, ante el Rey o sus representantes -Virreyes en América-. Y por supuesto no se menciona en ninguna parte que algún otro cuerpo oficial saliera con mazas propias, caso de tenerlas sin concesión real -que es lo válido-, y esto, pensamos nosotros, porque al evento no se le da, por los tratadistas de tales cuestiones, la mínima importancia.

El Pendón o insignia máxima del Cabildo es, con eminente categoría, la seña del dominio y potestad real. En Sevilla nunca se discutió la preeminencia de que fueran los regidores los encargados de portarlo, seguramente por la circunstancia de haberlo llevado desde el primer momento el Alguacil Mayor en las campañas contra el musulmán en cuantas ocasiones tuvieron que intervenir las milicias concejiles, y más tarde (1558) el Alférez Mayor, lo que dio lugar a que arraigara la costumbre con gran estabilidad ${ }^{9}$.

Matíz diferente encontramos en el llamado Guión o Estandarte Real en Indias, que podían llevarlo en habituales "paseos" algunos oficios más elevados que los del Cabildo Secular, por ostentar la representación del Monarca. En el caso concreto de Guatemala y en un primer término, el Presidente a la cabeza de la Audiencia como Gobernador y Capitán General. Por el hecho de tratarse de tierras tan apartadas de España, esta insignia, en los actos públicos, era considerada muchas veces no privativa del Ayuntamiento. Precisamente por esa lejanía de la Corona, todas las autoridades estaban muy necesitadas de los signos externos por los cuales "se imprimía el respeto a la autoridad y se afianzaba el vasallaje" 10 .

Por semejante razón en el año 1659 solicita el Cabildo de Santiago mediante carta al Rey, que se le restituya el privilegio de poder portar el guión

7. Archivo General de Indias. Sección V. Gobierno, 4) Audiencia de Guatemala. Legajo 42. El Rey al Cabildo. 12 septiembre 1600 .

8. Ariño, Francisco: Sucesos de Sevilla.- Desde 1592 a 1604. pág. 293.

9. González Vargas, op. cit. pág. 23.

10. A.G.I. Guatemala. Leg. 483. El Presidente de la Audiencia al Secretario de Estado. 3 diciembre 1803. 
en procesiones y actos públicos, cuya costumbre, se dice al pie de la letra, "se había perdido por haberse introducido en este género de honor los ministros de la Audiencia y cuya pretensión no se puede seguir ante ella por haber de ser los mismos jueces los interesados"11.

La insignia real como decimos, magnificó todos los actos civiles y festividades religiosas a que asistía el Cabildo en cuerpo de Ciudad. La Plaza Mayor de Santiago y la de San Francisco de Sevilla, ambas ornadas por bellas fuentes, según los historiadores, fueron los escenarios oficiales de todo tipo de representación civil, desde la más excelente, la ceremonia de alzar pendones por los monarcas que comenzaban su reinado, hasta las tan famosas "corridas". En Santiago se lidiaron toros por primera vez en el año 1573 con motivo de la recepción del Presidente Gobernador Don Pedro de Villalobos ${ }^{12}$. Sevilla en estas y otras fiestas, como los renombrados torneos y juegos de cañas, dio siempre la mejor nota de esplendidez al intervenir en ellas los nobles capitulares con su derroche y fama de extraordinarios jinetes, lo que vino a culminar más tarde, en 1670 , con la fundación de la Real Maestranza de Caballería. Como en las crónicas de Santiago de los Caballeros, están reseñadas prolijamente, en los anales hispalenses, con todo lujo de detalles, las ceremonias reales. Las de Felipe II y Felipe V, por la insistencia de los autores, parece que fueron en la Edad Moderna las de mayor suntuosidad en ambas ciudades. Por razones de brevedad y carácter de este estudio, no nos vamos a ocupar de su relato.

Daremos buen final a la cuestión de la imagen pública de estos cabildos y sus semejanzas, con una simple reseña de la vestimenta. La afición a la ostentación y en su consecuencia al lujo, ocupó un lugar importantísimo en el ánimo de los capitulares, dado que, como todos los oficios de España y de las Indias, se identificaban plenamente con el cargo y su categoría. Los munícipes, que tenían además, como hemos dicho, una clara conciencia de su primacía, por aquello de la representación popular exclusiva, procuraban, como algo muy necesario, superarse ante los demás cuerpos con sede en el ámbito urbano. Apuntemos que durante toda la época medieval y la moderna fue una constante en la sociedad española el vestir con lujo excesivo; y naturalmente, para aquellos que se sabían sus más directos representantes, se llegó a convertir el asunto en una verdadera preocupación. Así se pone ampliamente de manifiesto en todos los documentos en que se viene a tratar de la inmejorable estampa que tenían que dar, repetimos, los que simbolizaban a la Ciudad.

11. A.G.I. Guatemala. Leg. 20. La Ciudad al Rey.

12. Pardo, op. cit. Año 1573, 26 enero. 
Ahora bien, por jugar fuertemente en estos empeños el factor de la posibilidad de variación de atuendos, los Cabildos y Regimientos se presentaban en público con sorprendente vestuario, según las ocasiones lo requerían, por la mayor o menor solemnidad de los actos. Las novedades pues de sus trajes de gala dejaban estupefacto al vecindario, y el esplendor queda hartamente probado en las múltiples descripciones que se conservan al respecto. En Sevilla se contó desde los ropajes de largas túnicas con riquísimas telas de terciopelo y damasco, ornadas de perlas, bordados y joyas, con toquetes y gorras, hasta un variado cambio posterior a capas, chaquetas, chupas, jubones, calzas y sombreros empenachados... Los lutos, asimismo eran rigurosamente expresados en los atuendos y acompañamientos. Todo, naturalmente, siguiendo el dictado de la moda más exigente. Hay un descargo que siempre nos ha llamado la atención. Dice Ortiz de Zúñiga en sus Anales ${ }^{13}$ que "el lujo es disculpable por lo que engrandece el ánimo y por el lustre general que da a la Ciudad". Pero lo cierto es que se llegó a tal exceso que la Corona, por explicables razones políticas, tuvo que llegar a suprimir, sobre todo, las telas de oro y plata, y en esa misma línea se sucedieron firmes leyes suntuarias para todos sus dominios. Ante las prohibiciones reales, los cabildos generalizadamente, comenzaron a clamar por uniforme propio. Concretamente en Sevilla, ¿Cómo iba a destacar la Ciudad con el severo traje español, tan popularizado y de uso obligado para todos los estamentos oficiales en los años postreros del siglo XVII e iniciales del XVIII? ¿Podía tolerar esto el Ayuntamiento en el ámbito hispalense donde la mayoría de las representaciones iba haciéndole la competencia y a veces superándolo con su aspecto de una mayor riqueza en ciertos detalles? Imaginemos la variada concurrencia: La Real Audiencia, el Cabildo Eclesiástico, la Casa de la Contratación de Indias, la Real Maestranza de Caballería, el Claustro Universitario...

No queriendo abandonar el Cabildo de Sevilla el traje de color que a veces se le permitía usar, se suceden las peticiones del Ayuntamiento a la Corona para usar uniforme "privativo" que lo destacara de los demás, con una insistencia rayana en la pesadez; y he aquí que la ya por entonces Muy Noble, Muy Leal y Muy Heróica Ciudad, lo consigue al fin oficialmente en 1824 alcanzando su deseo secular con un modelo napoleónico de casaca azul, vueltas de grana y sombrero de tres picos, que hubiera espantado a los que por primera vez suscribieron la solicitud.

Pero volvamos a Santiago de los Caballeros donde ocurría otro tanto, según se desprende de las distintas descripciones de los trajes de sus regidores. Hay que admitir que Sevilla les aventajaba en lujos ya que eran notorias

13. V. Guichot y Parody, Joaquín: Historia de la Ciudad de Sevilla. Sevilla, 1875, T. III, pág. 504. 
las diferencias sociales y la ciudad guatemalteca venía arrastrando un prolongado cúmulo de penurias y apariencias casi heróicas que arrancaban del siglo $\mathrm{XVI}^{14}$.

En Madrid, a treinta y uno de mayo de 1785, el Apoderado del Cabildo de Santiago de Guatemala solicita un uniforme para los individuos del Cuerpo Capitular, que se concede por Real Orden de cuatro de mayo del año siguiente. Se pidió con vistas a las asistencias y funciones públicas y se decía, para mantener lustre, decoro y honor, porque esto daba a conocer, así distinguidos del restante vecindario, la autoridad de los empleos, y les hacían más atendidos y respetables. He aquí el modelo: "De terciopelo negro, con chupa y vueltas de tisú, para días de mayor gala, y el pit o pequeño uniforme de tafetán o raso"15. Este traje se viene a identificar con el que usó el Ayuntamiento Sevillano en la aclamación de Carlos IV el año $1788^{16}$. Sin embargo el citado atuendo es difícil considerarlo -a pesar de la concesión oficial- como un uniforme de uso exclusivo, puesto que no es más que el referido traje español que asimismo usaban los oficios de otros cuerpos, salvo pequeñas variaciones en los adornos. Desde más antiguo todavía la Ciudad de Santiago tenía previstas todas las situaciones imaginables en este apartado, para no faltar a ningún género de oportunidad. Fue publicado un acuerdo capitular en diecisiete de abril de 1607 que dice textualmente: "Desde el presente año asistirá el Ayuntamiento a la procesión del Santo Entierro del Templo de Santo Domingo a sacar las sagradas insignias usando lobas de tafetán negro"17. Es decir, sotanas.

Las influencias hispalenses en América son ya bien conocidas pues diversos investigadores como Constantino Bayle afirman que los municipios y las catedrales de la América Hispana se rigieron por Sevilla ${ }^{18}$. Aún más interesantes nos resultan los inteligentes comentarios de Muro Orejón sobre una Real Cédula de 1738 , promulgada precisamente ante un problema de precedencias de oficios en las Indias. En el documento en cuestión se habla de las "prácticas que se observan y guardan en la ciudad de Sevilla y su Ayuntamiento de donde se tomaron y mandaron tomar las reglas para la formación de mis ayuntamientos de mis Indias" 19 . Nótese que se habla en pretérito. De ahí el impacto que efectivamente tuvo en el Nuevo Mundo tan notorio modelo sevillano recordado insistentemente por la Corona, no sólo de tiempo atrás, sino, como vemos, en estas fechas de la recién estrenada dinastía real de origen francés, en que los asuntos de la antigua y rígida ceremonia se repasaban intensamente y estaban al rojo vivo.

\footnotetext{
14. V. Sanchíz Ochoa, op. cil. cap. III.

15. A.G.I. Guatemala. Leg. 645. Expediente.

16. Gil, Manuel: Relación de la Proclamación del Rey Don Carlos IV y Fiestas con que la celebró la M.N. $y$ M.L. Ciudad de Sevilla. Madrid, 1790. pág. 37.

17. Pardo, op. cit.

18. Bayle, op. cit pág. 10.

19. V. Muro Orejón, Antonio: "El Ayuntamiento de Sevilla modelo de los municipios americanos". Anales de la Universidad Hispalense. Vol. XX. Año 1960. n. ${ }^{\circ} 1$.
} 
En las salidas públicas a funciones religiosas adquieren los antiguos cabildos y regimientos muy especialmente un protagonismo que produce verdadero asombro. Refiriéndose a estos acontecimientos hemos comprobado en el siglo XVI que incluso los textos legales, hablan de "las fiestas que la Ciudad de Sevilla como propias suyas hace" y notamos que se trata de procesiones a las que el Cabildo simplemente acudía ${ }^{20}$. Dichas salidas tuvieron su mayor importancia, desde el punto de vista de su ceremonial, durante el máximo esplendor de la Casa de Austria.

También se observa que, durante un largo período de tiempo viene en compañía del Ayuntamiento, precediéndolo, toda una serie de elementos organizados. Esto ocurre tanto en Sevilla como en Santiago de los Caballeros, en ocasiones de gran solemnidad, así la de la procesión del Corpus Christi donde aparecían abriendo paso a la Ciudad con un gran regocijo, la Tarasca, los Gigantes y las Danzas. En 1710 dispone el Ayuntamiento de Santiago "que la Tarasca se haga de gonces y no como era enantes"21. Está claro que se decidía por este acuerdo municipal, librarla de su originaria rigidez para conseguirse así un mejor movimiento al son de la música. En el ínterin, se hace famosa en Sevilla la salida del Tarasquillo del propio cuerpo de la Tarasca, para divertimiento del pueblo y de la chiquillería. Las Danzas, aunque alguna vez lo intentaron, no podían entrar en el recinto sagrado de la Catedral Hispalense, por grave apercibimiento del Cabildo Eclesiástico y oposición tajante del Obispo $^{22}$. En Guatemala, distinta mentalidad, se recomendaba por la propia autoridad del Presidente de la Audiencia, "meter las Danzas en la Iglesia en la Procesión del Santísimo Sacramento"23.

No pretendemos decir, con lo anteriormente expuesto, que estos frívolos aditamentos, ni todo el bello conjunto realizado por los artífices gremiales, formaran cuerpo con el Cabildo Secular, si bien no se puede negar que de este modo se conseguía un marco festivo para su pleno lucimiento. Estaban los regidores sumamente empeñados en ello, a la vista de la paulatina pérdida de sus atribuciones a favor de la Audiencia, en materia de administración de justicia, con la consiguiente pérdida de significado e importancia ante la opinión popular.

En la Plaza Mayor de Santiago de Guatemala, vecinos frente a frente los palacios de la Real Audiencia y del Cabildo de la Ciudad, era donde tenían lugar, como ya hemos apuntado, las formaciones y salidas públicas más interesantes y dignas de comentario. A mediados de la centuria del seiscientos se citan ocurrencias donde es relevante el lucimiento del Ayuntamiento dentro de una buena armonía con el Regio Tribunal, quizás en un tono demasiado exagerado

20. Ordenanzas de la Audiencia de Sevilla. V. González Vargas, op. cit. pág. 12.

21. Pardo, op. cit. Año 1710, 29 julio.

22. Matute y Gaviria, Justino: Noticias relativas a la Historia de Sevilla. Sevilla, 1886. pág. 155.

23. Pardo, op. cit. Año 1756, 9 julio. 
para nuestra mentalidad. Se nos cuenta, que con motivo de las celebraciones de 1658 por el nacimiento del Príncipe Don Felipe Próspero, dado a luz por la Reina Doña Mariana, hubo en el famoso recinto tres noches seguidas de fuegos de artificios en las cuatro esquinas y en el medio. Importa destacar que entre los regocijos o fiestas hubo una Encamisada en la que salieron todos los munícipes y dos carros de representación. Aclaremos que esto consistía en un espectáculo como de mojiganga, que se hacía ante la autoridad teniendo al pueblo de espectador. Dice así en la disposición del acto: "Que en la Encamisada en que habían de salir el Cabildo y Regimiento en la noche con los carros, llegasen hasta los corredores del Palacio donde habían de estar los Señores Presidente y Oidores de la Real Audiencia, y se debía de hacer la primera representación. Y que llegados allí se viniese la Ciudad a las Casas del Cabildo en la forma que había ido, dejando los carros en la representación a dicha Real Audiencia. Y que el Cabildo y Regimiento estuviese en los corredores de su casa, sentado en la forma de sus antigüedades, para que en acabando de representar a la Real Audiencia viniesen los carros e hiciesen la misma representación a la Ciudad que habían hecho a la Real Audiencia y que acabada, se guardase la forma que entonces diese dicho Cabildo ${ }^{24}$.

También en Sevilla se mezclaban ciertos disfraces en las fiestas de la Plaza de San Francisco. En fecha muy cercana dice Ortiz de Zúñiga en sus Anales, año 1671, que se acompañaban los caballeros hispalenses con "lacayos y lacayuelos en trajes de turcos y moros cautivos que hasta arrastraban cadenas" y añade, "emulando sucesos de la Reconquista". Pensamos que los citados señores no iban en este caso representando al Cabildo, aunque tal vez muchos de ellos fueran sus más destacados componentes y la intención quizás no sería otra que emular hechos gloriosos en que habían participado sus nobles antepasados.

Todo esto lleva a considerar que los cabildos participaban de alguna manera de iniciativas anárquicas en cuestiones de orden o etiqueta. Ellos, según conviniera a sus razones, tomaban a veces algún que otro acuerdo sin respaldo legal. En el año 1660 se resuelve en Santiago poner en práctica la recepción del Señor Obispo bajo palio y por ello, el Presidente de la Audiencia, alarmado por la determinación municipal, tiene que recordarles que "esto no se permite en ninguna parte de las Indias sino para los virreyes por representar a la persona de Su Magestad"25.

El Cabildo de Sevilla tampoco se quedó corto en lo de tomar acuerdos por su cuenta y razón, sobre todo en circunstancias de sentirse menospreciado, y

24. A.G.I. Guatemala. Leg. 20. Carta de la Ciudad de Santiago al Rey. 1 julio 1658.

25. A.G.I. Guatemala. Leg. 20. El Presidente de la Audiencia a la Ciudad. 
ciertamente sin estar amparado más que por sus propios intereses y vanidades. Después de un larguísimo proceso, al final del siglo XVIII, mantenía en muchos terrenos su postura de intransigente particularismo. Para poner un ejemplo, no quería salir en forma de Ciudad a funciones de Iglesia los días en que se hicieran justicias de horca en la Plaza de San Francisco. Esto iba contra su decoro... Cada vez que se presentaba tan lamentable caso, debatía insistentemente con la Audiencia, se tomaba el acuerdo de no salir, y, a seguidas, se presentaba el oportuno recurso de apelación ante el Supremo Consejo ${ }^{26}$. Sin privilegio, pero basándose en la fuerza de su razón y de su categoría. ¿Cómo iba a soportar esto tan noble Cabildo de medio centenar de individuos que el año 1787 cuando la jura de Carlos IV, aparecen en público montados en soberbios caballos andaluces, acompañados de maceros también montados, con ropones largos y mazas de oro al hombro y escudos del mismo rico metal al cuello con las armas de Sevilla ${ }^{27}$ ? Defensa de la dignidad a todo trance.

Cosas parecidas ocurrían en Santiago. En el año 1692 durante una asistencia del Ayuntamiento al Palacio Real se produce una enérgica reclamación del Cabildo. Se dice literalmente en la propuesta que "no era decente que se mezclara la Ciudad en el salón con toda la gente que allí concurría y en especial con los pajes del Presidente..."28. Esto de no querer confudirse con la "plebe" tal y como se expresa en muchos documentos, es una constante. Los Cabildos, herederos de una nobleza autoritaria y pagada de sus privilegios, se apoyaron durante largos años en las propias tradiciones y costumbres y con ello mantuvieron más adelante firmes las disposiciones de su Ceremonial hasta desaparecer la vigencia del mismo por razones históricas y políticas.

26. Matute y Gaviria, op. cit., Año 1799.

27. V. Guichot y Parody, 1896. T. III, pág. 147.

28. A.G.I. Guatemala. Leg. 42. Autos sobre diversas pretensiones de la Ciudad. Año 1692. Expediente. 